\title{
Introducing a Trauma Registry in Mozambique: An Ethics Case Study
}

\author{
Fadi Hamadani1 ${ }^{*}$, Otilia Neves ${ }^{2}$, Ana Olga Mocumbi ${ }^{2}$, Tarek Razek ${ }^{1}$, Kosar Khwaja1, \\ Paola Fata', Andrew Beckett ${ }^{1}$, Eunice Jetha ${ }^{2}$, Dan L. Deckelbaum ${ }^{1}$ \\ ${ }^{1}$ Centre for Global Surgery, McGill University Health Centre, Montreal, Canada \\ ${ }^{2}$ Instituto Nacional de Saúde (National Institute of Health), Ministério da Saúde (Ministry of Health), \\ Maputo, Mozambique \\ Email: ${ }^{\text {fadi.hamadani@mail.mcgill.ca }}$
}

Received 23 June 2014; revised 22 July 2014; accepted 10 August 2014

Copyright (C) 2014 by authors and Scientific Research Publishing Inc.

This work is licensed under the Creative Commons Attribution International License (CC BY).

http://creativecommons.org/licenses/by/4.0/

c) (7) Open Access

\begin{abstract}
This paper presents a case study of implementing a trauma registry in Mozambique, a low-income country with limited current trauma surveillance. An outline of the importance of trauma registries is presented followed by an evidence-based approach to building a sustainable and ethical partnership with local stakeholders.
\end{abstract}

\section{Keywords}

Global Burden of Injury, Global Health Ethics, Trauma Registry in Low-Income Countries, Trauma System in Low-Resource Settings, Global Health Partnership

\section{Introduction}

\subsection{Defining the Global Scale of Injury}

Injury results in more annual deaths than HIV, malaria and tuberculosis combined [1]. The social and economic burden of injury is profound, and disproportionately affects young people, the most productive demographic of the population. The $21^{\text {st }}$ century has brought a shift in the understanding of causes of death across nations worldwide, in high- and low-income countries alike. Documented deaths from infectious diseases have declined, while statistics on deaths from injury have increased, becoming the leading cause of death in many developing countries [2]. Accordingly, the World Health Organization (WHO) has predicted a 40\% increase in global deaths caused by injury between 2002 and 2030 [3]. In spite of these projections, little action has been taken,

${ }^{*}$ Corresponding author.

How to cite this paper: Hamadani, F., Neves, O., Mocumbi, A.O., Razek, T., Khwaja, K., Fata, P., Beckett, A., Jetha, E. and Deckelbaum, D.L. (2014) Introducing a Trauma Registry in Mozambique: An Ethics Case Study. International Journal of Clinical Medicine, 5, 949-955. http://dx.doi.org/10.4236/ijcm.2014.516127 
particularly in low-income countries where the focus remains on the morbidity and mortality related to infectious diseases, especially HIV/AIDS [4]. Moreover, projections show that in developing countries, road traffic deaths will increase by 83\%, between 2000 and 2020 [5]. In contrast, there will be a further $30 \%$ decline in road traffic deaths in developed countries, continuing a pattern that has been established in recent decades [5]. This pattern, which has emerged in high-income countries (HICs) but not in low- and middle-income countries (LMICs), can be attributed to the widespread use of trauma care systems and informed prevention strategies. It has been demonstrated that people with life-threatening but potentially treatable injuries are up to six times more likely to die in a country with no organized trauma system than in one with an organized, and well-resourced trauma system [6]. Such evidence demonstrates the need for deployment of trauma systems, including the use of trauma registries, which have been identified as an essential instrument in decreasing death and disability rates from injuries [7].

\subsection{How Do Trauma Registries Improve Injury Outcomes}

Trauma registries have been in existence for more than three decades in HICs, a process that allows for local, national and international benchmarking and performance improvement [8]. Registries are now treated as an essential component of sophisticated trauma systems. Trauma registries are designed to provide information that can be used to improve the efficiency and quality of trauma care, thereby improving patient outcomes by identifying injury distribution by age, geographic location, and cause of injury. Ultimately, trauma registries provide a means of collecting and analyzing pertinent epidemiologic data that can be used for the purposes of performance improvement, injury prevention, generating awareness, and further policy measures to reduce the burden of injury.

\section{Ethics Case Study—An Evidence-Based Approach to Setting up a Global Health Partnership}

\subsection{General Principles of Building an Ethical Global Health Partnership}

Setting out to implement a trauma registry in a low-income country is an important and challenging goal and its accomplishment will depend on a sound ethical approach. In addition to a thorough understanding of the resource gaps and health care needs of the host nation, success is only achievable when local leadership and accountability are established very early in the process. Furthermore, formalized agreements based on transparency and engagement with local stakeholders will ensure improvements in health outcomes that are tangible and sustainable. Respect for local processes and regulations are essential just as they are in high-income countries. Finally, the fair distribution of responsibilities, while ensuring equitable representation of local partners in authorship and dissemination of the work are important to introduce policies that can be up-scaled effectively.

In an important paper on the ethics of global partnerships in low resource settings, Collins (2014) set out to define a road map of steps that ensure project success within a robust ethical framework when working in the global arena [9]. In the current era, population interconnectedness is occurring on a global scale that often demands that health strategies be implemented in such a context. If not carefully thought-out, this approach risks alienating the local and highly individualized needs of the host country and grassroots partner [9]. As a first step it is crucial that any outside entity working in a foreign environment understand the local setting. Most important is the understanding that the local capacity has the expertise to work within their environments and should therefore be the principle drivers of the respective program. It is important to recognize the given expertise of involved parties and the importance of sharing and respecting such expertise to create successful programs that are locally relevant and not based on foreign agendas.

Additional considerations include awareness and understanding of the unique set of customs and values that make up the local culture. These preconceptions may include religious and cultural views that need to be taken into account if viable health care interventions are to be delivered. It is also important to scale every intervention to allow for respect of local social hierarchies and social customs [9] [10].

\subsection{Identification of Locally Relevant Gaps}

Mozambique is a nation in Southern Africa with a population of 24 million people (2011 census) and a per capita GDP of \$650 [11]. According to the Gini index of human development Mozambique has a score of 45.7 
(2008) [12] [13] placing it on the medium scale of this index. According to the United Nations Human Development Index scale it is a low resource country with a score of 0.322 (2011) [13]. Few studies have quantified the true scale of injury in Mozambique and most data to date has come from local monitoring bodies and government registries that are limited by missing data.

An important study by Romao et al. in 2003 attempted to quantify the burden of road traffic crashes in Mozambique using incomplete data sets [14]. Focusing on the period 1990-2000 and utilizing information from the National Institute for Road Safety the authors were able to conclude that the burden of road traffic injuries in Mozambique is rising, with at least three people killed daily [14]. The main causes of crashes include reckless driving, drunk driving, roads with potholes, inadequate signs, lack of protection for pedestrians, and inadequate traffic law enforcement [14]. Attempts to further characterize the burden of injury are made difficult by the fact that there are currently no hospital-based trauma registries in place. Our goal emerged from this need, and we undertook the task with our local Mozambican partners to introduce a trauma registry in two hospitals in Mozambique with plans to expand to all hospitals with trauma in the country. The implementation of a trauma registry will provide the earliest hospital-based injury epidemiology in Mozambique, which will inform targeted interventions in education and prevention, address human and material resource gaps, and drive policy to attend to the challenges of injury.

\subsection{Local Accountability and Leadership_-Setting up a Working Partnership in Mozambique}

The most important step to undertake when partnering with local organizations and government is a comprehensive assessment of the area's health care needs and resource gaps. It is important to conduct a thorough analysis of existing programs and policies in the context of current local demographics, health services, burden of disease, and established programs. Stemming from this step is the identification of local leadership and accountability for the project. As previously discussed, it is the local leadership that has the expertise to best understand existing gaps and to address significant health challenges such as trauma. In addition, it is the local leadership and health care practitioners that understand the existing infrastructure, both human and material, that is crucial for program implementation and development.

An important step in the program implementation is formalizing the relationship between relevant partners. This can be achieved with the signing of a memorandum of understanding, which allows the parties to define a plan of action that is flexible and sensitive to the needs and obligations of both partners. Included in such a memorandum are terms that allow for continuous monitoring and feedback that is used to adapt and modify the project as the need arises. Partners should discuss their objectives and needs in a comprehensive manner that encompasses all aspects of the project. Incentives agreed to by each partner, including financial contributions, technology, training courses, or human expertise and time should be included in the understanding.

A partnership was undertaken between the Centre for Global Surgery (CGS) at the McGill University Health Centre in Montreal, Canada and local Mozambican partners has been designed to accomplish the task of introducing a trauma registry to the country. Using the principles discussed above, the strategy in Mozambique has been to build a strong relationship with both the local health leadership and government. The initial step was a site visit by our group, including the co-director of CGS, which enabled us to understand the local demographics, health care system and infrastructure including distribution of health care providers and facilities, and to identify other organizations engaged in potentially similar activities to prevent duplication of work. Our experience revealed that by emphasizing the role of the local partners and ensuring their leadership in all phases of the project, from conception to implementation, results in a true partnership with higher likelihood of program sustainability and growth.

\subsection{Key Principles to Promote Sustainability_Training, Monitoring, and Evaluation}

The primary objective of any global health partnership, whether clinical or developmental in nature, should ensure a long-term and sustainable outlook. [15]-[17] based on the following principles:

- Ensuring good outcomes by integrating a strong educational component to their goals, thus supporting the local health care infrastructure, which is often strained, to deal with complications and obstacles that may arise in the wake of the project [18].

- Allocating fairly the available resources, including local teachers and experts, between the foreign and local 
partners [19].

- Promoting investment in local allied health care development as countenance to the local health infrastructure.

- Properly managing funds and resources, which may be used wisely to reinforce the partnership with both grassroots local clinical leadership as well as administrative and governance leadership [9].

To ensure sustainability, education played a key role in our project. Visiting experts, researchers, and health care providers participated in relevant education for trauma registries using the concept of "train the trainer" ensuring long-term integrated plan and not just a short-term experience [9] [17]. Several didactic and hands-on sessions were provided to properly train local partners in the effective use of the technologies being used to collect data on injury. Training sessions set the stage for the project and put the goals within the context of local health care priorities and cultural relevance. It is important to conduct sessions to generate awareness on the importance of the project. This is done most effectively by the local leadership which are much more likely to successfully convey the message than the visiting team. The introduction of projects and research in resourcelimited settings may often be viewed as just extra work in an already strained environment. Therefore, one may face understandable reluctance and hesitation to taking on more work. This resistance can be overcome by ensuring that program managers, health care practitioners from relevant specialties, hospital administrators, and relevant Faculty leadership are all part of the implementation team. Undergraduate and postgraduate students are also involved in overseeing the registry, which will play an important role in their training as future leaders of such projects.

Program monitoring and evaluation is critical to the success and needs to be implemented at the time of project commencement. This too needs to be spearheaded by local participation. Each site was designated a local program coordinator who ensures proper data collection by meeting with the grassroots staff on weekly basis and reviewing the pertinent metrics of the registry regularly. These individuals are usually senior allied health professionals and coordinators who are respected within their work environments. Their input and decisions greatly facilitated the implementation of all key steps of the project. The visiting team has to establish a continuous stream of communication and be available to conduct regular meetings when needed. Concerns and requests by the host country need to be discussed in conjunction with all partners and collective decisions can then be made. Importantly, we found it very helpful to ensure that the host participants also have an opportunity to travel to the visiting country in order to participate in educational initiatives and further training. This will allow the host partners to gain a direct knowledge and experience with the realities on the ground in the health care system and build lasting personal relationships with the grassroots teams locally—-this need diminishes rapidly as the local leadership gains independent capability to maintain and manage the data systems and educational programs.

\subsection{Ethics Approval and Respect for Local Processes}

Ethics approval from both partner institutions should be sought and obtained prior to beginning the project. Respect should be paid to the different requirements of the process in each locale. For example, in Canada ethics approval is usually obtained by applying to the local Institutional Review Board with a standard proposal. In Mozambique this process involved the submission of a detailed proposal along with several meetings with representatives of the local Ethics Board. In situations where data may be shared between institutions, it is essential that the data be de-identified, stored and protected in adherence to all of the institutions' regulatory processes. Involving the local leadership again emerged as an important theme in seeking ethics approval, as they have had to go through the steps many times themselves, and the advice and support offered is essential for the approval process. The ownership of the data is of primordial importance. While such projects are often implemented collaboratively, one must always remember the origin of the data and that it is under the ownership of the host entities [20]. Failure to respect this principle is a significant breach of the collaborative spirit of global partnerships.

Respect for local processes extends beyond just obtaining ethics approval, which is seen in many institutions as an approval for the research component of a project. Buy-in and support from local stakeholders is ultimately the only mechanism that can ensure success. As such, we focused our efforts on identifying the leadership of each unit involved in the deployment of the registry and involving them as partners early on. We obtained early approval from our government partners to start the project and this helped to introduce the registry as a new health policy. Beyond government approval it is also important to obtain the relevant local administrative approvals before work commences. By involving the pertinent players and obtaining their support of the registry in 
the early phases we ensured that the policy became a part of the local administrative structure with investment from all levels.

\subsection{Financial Considerations}

An interesting issue that arises when dealing with global health partnerships is the nature of the financial relationship between partners [9] [21] [22]. An important principle for program success is to focus on the work at hand and not solely on the financial support structure [23]. Addressing priority gaps (such as injury) identified by local leadership encourages commitment towards program implementation. It is therefore the local leadership that should drive the financial support structure. To mitigate some of the costs, programs may be embedded into existing structures. For example, surgical trainees or nurses complete data collection while they evaluate injured patients. For the registry to be completed, the trainee must have an understanding of patient demographics, mechanism of injury, and examine the injured victim. This information impacts patient outcomes and is therefore not purely for research purposes.

The financial contributions of the foreign team are a point of interest. One must recognize that for true sustainability and independence, programs should not be foreign donor dependent. In fact, much of donor grants never actually reach host nations [24]. We provided the tablet technology and covered a lot of the costs associated with setting up the registry technology as well as financing the trips. The literature lacks work that deals directly with the issue of financial ethics in global health partnerships [22]. It is important for each side to be responsible for a certain aspect of the project, their respective investment, with the intended consequence of tangible health improvements. The local partners provide investment by administering and managing the project while the visiting nation may assume the financial responsibility in the early phases of the project. This agreement fits into the context of a developmental paradigm. The best way to ensure transparency and an effective utilization of resources is by establishing an accord or agreement between both partners in the early stages of partnership.

\subsection{Dissemination of Work with Equitable Partner Representation}

Research serves as a constructive component of any global health partnership. It is important to involve members of both sites equally and to ensure that research opportunities are created at both visiting and host nations for learners from both sites [25]. We have found that by involving students in the process of completing their studies we can ensure a long-term commitment from both parties. Furthermore, by constructing research around the nature of the project, important lessons are gained by both partners and new and creative ways of accomplishing targets are met.

Stemming from research is the issue of authorship. Smith et al. (2013) tackled this important issue in their paper on the nature of authorship ethics between low- and middle-income countries and high-income countries [26]. They identify important systematic limitations in current international research. First amongst these is the issue of English as a language of authorship, which leads to inadequate distribution of writing requirements when the hosts work in a different language [26]. Secondly, the issue of power distribution discussed above in a financial context may also arise when it comes to authorship distribution between host and visiting country [26]. Finally, the authors discuss the role of editorial bias towards Western researchers in publishing works [26].

Adhering to many of the principles discussed earlier, such as local accountability for program implementation and development, data ownership, and transparency addresses many of these concerns. This approach will result in equitable authorship distribution respecting all involved parties. In 2011, Kushner et al., along with the Editorial Board of the World Journal of Surgery, ushered in a new policy at the journal whereby research that emanates from global partnerships will no longer be accepted for publication without authorship representation from host nations [27]. These principles are becoming ever more important in global partnerships and they need to continue to be recognized as such.

\section{Conclusion}

The number of international academic partnerships and global health programs is expanding rapidly. Although the benefits of such programs to visiting international partners have been well documented, the perceived impacts on host institutions in resource-limited settings have not been assessed adequately. We provide here an overview of our experience establishing an important public health policy initiative in a low-resource country, utilizing the literature available on the issue as an evidence-based blueprint for the successful implementation of 
a long-term partnership. Many questions remain unanswered, but it is becoming evermore evident that creating a long-term partnership based on transparent communication and ensuring appropriate distribution of responsibilities, program accountability, and program development, will promote successful interventions in Global Health.

\section{References}

[1] Lim, S.S., et al. (2013) A Comparative Risk Assessment of Burden of Disease and Injury Attributable to 67 Risk Factors and Risk Factor Clusters in 21 Regions, 1990-2010: A Systematic Analysis for the Global Burden of Disease Study 2010. The Lancet, 380, 2224-2260. http://dx.doi.org/10.1016/S0140-6736(12)61766-8

[2] Mock, C.N., et al. (1998) Trauma Mortality Patterns in Three Nations at Different Economic Levels: Implications for Global Trauma System Development. Journal of Trauma, 44, 804-812. http://dx.doi.org/10.1097/00005373-199805000-00011

[3] Bickler, S.W. and Spiegel, D. (2010) Improving Surgical Care in Low- and Middle-Income Countries: A Pivotal Role for the World Health Organization. World Journal of Surgery, 34, 386-390. http://dx.doi.org/10.1007/s00268-009-0273-2

[4] Bhalla, K., et al. (2010) Availability and Quality of Cause-of-Death Data for Estimating the Global Burden of Injuries. Bulletin of the World Health Organization, 88, 831c-838c. http://dx.doi.org/10.2471/BLT.09.068809

[5] Bhalla, K., et al. (2009) Methods for Developing Country Level Estimates of the Incidence of Deaths and Non-Fatal Injuries from Road Traffic Crashes. International Journal of Injury Control and Safety Promotion, 16, 239-248. http://dx.doi.org/10.1080/17457300903402184

[6] Ciesla, D.J. (2007) Trauma Systems and Access to Emergency Medical Care. Journal of Trauma, 62, S51. http://dx.doi.org/10.1097/TA.0b013e31806546eb

[7] Mehmood, A. and Razzak, J.A. (2009) Trauma Registry-Needs and Challenges in Developing Countries. Journal of the Pakistan Medical Association, 59, 807-808.

[8] Nathens, A.B., Brunet, F.P. and Maier, R.V. (2004) Development of Trauma Systems and Effect on Outcomes after Injury. The Lancet, 363, 1794-1801. http://dx.doi.org/10.1016/S0140-6736(04)16307-1

[9] Collins, E.M. (2014) Developing Health Care Clinic Partnerships in Resource-Limited Regions. Pediatrics, 133, 574576. http://dx.doi.org/10.1542/peds.2013-3946

[10] Collins, J.P. (2011) International Consensus Statement on Surgical Education and Training in an Era of Reduced Working Hours. Surgeon, 9, S3-S5. http://dx.doi.org/10.1016/j.surge.2010.11.008

[11] Jones, E.S. and Tarp, F. (2012) Jobs and Welfare in Mozambique: Country Case Study for the 2013 World Development Report. The World Bank, Washington DC.

[12] Dgedge, M., Novoa, A., Macassa, G., Sacarlal, J., Black, J., Michaud, C. and Cliff, J. (2001) The Burden of Disease in Maputo City, Mozambique: Registered and Autopsied Deaths in 1994. Bulletin of the World Health Organization, 79, 546-552.

[13] Nizamo, H., Meyrowitsch, D.W., Zacarias, E. and Konradsen, F. (2006) Mortality Due to Injuries in Maputo City, Mozambique. International Journal of Injury Control and Safety Promotion, 13, 1-6. http://dx.doi.org/10.1080/17457300500151705

[14] Romao, F., Nizamo, H., Mapasse, D., Rafico, M.M., José, J., Mataruca, S., et al. (2003) Road Traffic Injuries in Mozambique. Injury Control and Safety Promotion, 10, 63-67. http://dx.doi.org/10.1076/icsp.10.1.63.14112

[15] Dacso, M., Chandra, A. and Friedman, H. (2013) Adopting an Ethical Approach to Global Health Training: The Evolution of the Botswana-University of Pennsylvania Partnership. Academic Medicine, 88, 1646-1650. http://dx.doi.org/10.1097/ACM.0b013e3182a7f5f4

[16] Elobu, A.E., Kintu, A., Galukande, M., Kaggwa, S., Mijjumbi, C., Tindimwebwa, J., Roche, A., Dubowitz, G., Ozgediz, D. and Lipnick, M. (2014) Evaluating International Global Health Collaborations: Perspectives from Surgery and Anesthesia Trainees in Uganda. Surgery, 155, 585-592. http://dx.doi.org/10.1016/j.surg.2013.11.007

[17] Deckelbaum, D.L., Ntakiyiruta, G., Liberman, A.S., Razek, T. and Kyamanywa, P. (2012) Augmenting Surgical Capacity in Resource-Limited Settings. Lancet, 380, 713-714. http://dx.doi.org/10.1016/S0140-6736(11)61090-8

[18] Hamadani, F., Sacirgic, L. and McCarthy, A. (2009) Ethics in Global Health: The Need for Evidence-Based Curricula. McGill Journal of Medicine, 12, 120.

[19] Seymour, B., Benzian, H. and Kalenderian, E. (2013) Voluntourism and Global Health: Preparing Dental Students for Responsible Engagement in International Programs. Journal of Dental Education, 77, 1252-1257.

[20] Denham, C.R., Classen, D.C., Swenson, S.J., Henderson, M.J., Zeltner, T. and Bates, D.W. (2013) Safe Use of Electronic Health Records and Health Information Technology Systems: Trust but Verify. Journal of Patient Safety, 9, 177189. http://dx.doi.org/10.1097/PTS.0b013e3182a8c2b2 
[21] Jones, F.A., Knights, D.P.H., Sinclair, V.F.E. and Baraitser, P. (2013) Do Health Partnerships with Organisations in Lower Income Countries Benefit the UK Partner? A Review of the Literature. Globalization and Health, 9, 38. http://dx.doi.org/10.1186/1744-8603-9-38

[22] Rybak, N., Koster, M., Gilbert, E.B. and Flanigan, T. (2013) Building International Collaborations from the Ground up: Brown University Partnerships in Haiti and Ukraine. Rhode Island Medical Journal, 96, 33-37.

[23] Deckelbaum, D.L., Ntakiyiruta, G., Liberman, A.S., Vassiliou, M., Rwamasirabo, E., Gasakure, E., Fata, P., Khwaja, K., Razek, T. and Kyamanywa, P. (2014) An Innovative Paradigm for Surgical Education Programs in Resource-Limited Settings. Canadian Journal of Surgery, in press.

[24] Savage, K. and Harvey, P. (2007) Remittances during Crises: Implications for Humanitarian Response. Overseas Development Institute, London.

[25] Pratt, B. and Loff, B. (2013) Linking Research to Global Health Equity: The Contribution of Product Development Partnerships to Access to Medicines and Research Capacity Building. American Journal of Public Health, 103, 19681978. http://dx.doi.org/10.2105/AJPH.2013.301341

[26] Smith, E., Hunt, M. and Master, Z. (2014) Authorship Ethics in Global Health Research Partnerships between Researchers from Low or Middle Income Countries and High Income Countries. BMC Medical Ethics, 15, 42. http://dx.doi.org/10.1186/1472-6939-15-42

[27] Kushner, A.L., Kyamanywa, P., Adisa, C.A., Kibatala, P., Mkandawire, N., Coleman, P., Kamara, T.B., Mock, C.N. and Hunter, J.G. (2011) Editorial Policy on Co-Authorship of Articles from Low- and Middle-Income Countries. World Journal of Surgery, 35, 2367-2368. http://dx.doi.org/10.1007/s00268-011-1255-8 
Scientific Research Publishing (SCIRP) is one of the largest Open Access journal publishers. It is currently publishing more than 200 open access, online, peer-reviewed journals covering a wide range of academic disciplines. SCIRP serves the worldwide academic communities and contributes to the progress and application of science with its publication.

Other selected journals from SCIRP are listed as below. Submit your manuscript to us via either submit@scirp.org or Online Submission Portal.
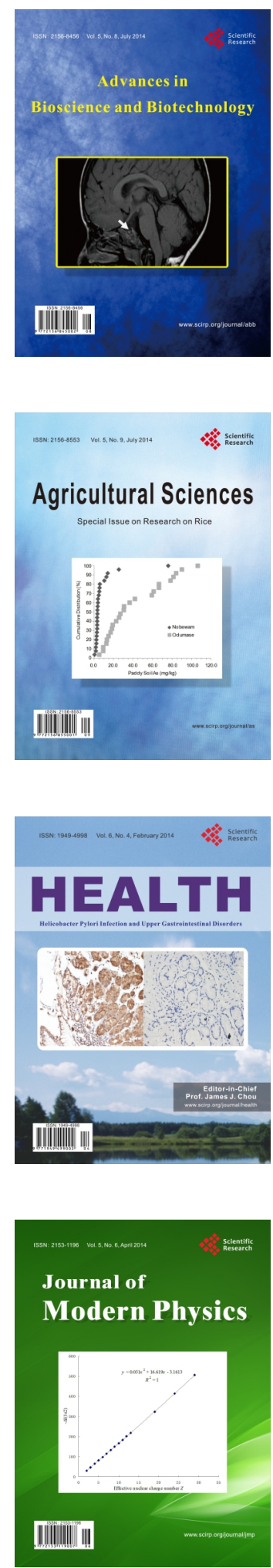
